\title{
International Society of Pediatric Oncology Staging System
}

National Cancer Institute

\section{Source}

National Cancer Institute. International Society of Pediatric Oncology Staging System. NCl Thesaurus. Code C140270.

A staging system for Wilms' Tumor that is based on the extent of tumor spread at surgery, after the patient has received neo-adjuvant chemotherapy. 